\title{
Assessment of Municipal Solid Waste Management System in a Developing Country
}

\author{
A. Ahsan, ${ }^{1,2}$ M. Alamgir, ${ }^{3}$ M. M. El-Sergany, ${ }^{4}$ S. Shams, ${ }^{5}$ \\ M. K. Rowshon, ${ }^{6}$ and N. N. Nik Daud ${ }^{1}$ \\ ${ }^{1}$ Department of Civil Engineering, University Putra Malaysia (UPM), 43400 Serdang, Selangor, Malaysia \\ ${ }^{2}$ Materials Processing \& Technology Lab, Institute of Advanced Technology, University Putra Malaysia (UPM), \\ 43400 Serdang, Selangor, Malaysia \\ ${ }^{3}$ Department of Civil Engineering, Khulna University of Engineering and Technology, Khulna 920300, Bangladesh \\ ${ }^{4}$ e-School of Health and Environmental Studies, Hamdan Bin Mohamed Electronic University, P.O. Box 71400 Dubai, UAE \\ ${ }^{5}$ Department of Civil Engineering, Faculty of Engineering, Institut Teknologi Brunei, \\ Bandar Seri Begawan BS8675, Brunei Darussalam \\ ${ }^{6}$ Department of Biological and Agricultural Engineering, University Putra Malaysia (UPM), 43400 Serdang, Selangor, Malaysia
}

Correspondence should be addressed to A. Ahsan; ashikcivil@yahoo.com

Received 4 October 2013; Accepted 20 January 2014; Published 27 March 2014

Academic Editors: M. W. Bo and L. Mai

Copyright (C) 2014 A. Ahsan et al. This is an open access article distributed under the Creative Commons Attribution License, which permits unrestricted use, distribution, and reproduction in any medium, provided the original work is properly cited.

\begin{abstract}
This study represents a few basic steps of municipal solid waste management practiced in the six major cities of Bangladesh, namely, Dhaka, Chittagong, Khulna, Rajshahi, Barisal, and Sylhet. A six-month field study was conducted to identify the solid wastes management steps such as storage at source, separation, on-site storage, collection, transportation, treatment, reuse, recycling, and ultimate disposal. This study addresses the role of the city authority to meet the demand of the city dwellers in solving this emerging socioenvironmental issue and the initiatives taken by some nongovernmental organizations and community based organizations. The problems and constraints of the solid wastes management system are also identified to find a sustainable management concept for the urban areas of Bangladesh.
\end{abstract}

\section{Introduction}

During the last few decades, the problems associated with municipal solid waste (MSW) management have acquired an alarming dimension in the developing countries. High population growth rate and increase of economic activities in the urban areas of developing countries combined with the lack of training in modern solid waste management practices complicate the efforts to improve the solid waste management services. In developing countries, the per capita generation of the solid wastes in urban residential areas is much less compared with the developed countries; however the capacity of the developing countries to collect, process, dispose, or reuse the solid wastes in a cost effective manner is significantly limited compared with the developed countries [1]. The wastes generated by human settlements and the associated problems are similar in the developing nations with variances between regions and locations based on geographic, sociocultural, industrial, infrastructural, legal, and environmental factors [2].

In Bangladesh, like in most developing countries, the solid waste management has so far been ignored and least studied environmental issues. Recently the concerned stakeholders have begun to consider this area to be an essential component to protect human health and nature. The urban population in Bangladesh has increased at a very steep rate of about $6 \%$ per year and concentrated mostly in six major cities, namely, Dhaka, Chittagong, Khulna, Rajshahi, Barisal, and Sylhet. Current estimations showed that about 13\% of total population and 55 to $60 \%$ of total urban population are living in these cities [3]. In these cities, the city authority, nongovernmental organizations (NGOs), community based 
organizations (CBOs), and private organizations are working together to manage the MSW system properly. However, the overall situation remains unchanged. It becomes evident that an integrated solid wastes management system (ISWM) is required considering the relevant socioeconomic settings and technological aspects of the country. To explore the possibility of adopting an ISWM, the limitations, constraints, and relevant experiences of existing management system are required to examine explicitly. For this purpose, a feasibility study has been conducted to identify the present status including problems and limitations of MSW management in the least developed Asian countries (LDACs) through a research project, shortly named as WasteSafe [3]. The MSW composition, generation, management, and recycling activities in Malaysia (another developing county) are reported by Ahsan et al. [4] and Samah et al. [5, 6].

Studies have been conducted in the six major cities of Bangladesh, namely, Dhaka, Chittagong, Khulna, Rajshahi, Barisal, and Sylhet, as shown in Figure 1, to identify the strengths and weakness at all levels of the existing wastes management systems starting from generation source to ultimate disposal. Data and related information were collected for the last six months through field survey, public consultation, literature, and other appropriate means [3]. Source storage and separation are done in an informal and uncontrolled way; hardly $30-40 \%$ of city dwellers practiced it. Door-to-door collection systems have been introduced recently for wastes collection from the sources (e.g., houses) and then transport of the waste to the nearest secondary disposal sites (SDSs). Wastes are collected from generation sources by NGOs, CBOs, and city authority by door-todoor collection systems. Where the door-to-door collection system is unavailable, residents dispose the waste in the nearest community bins, SDS, open land, road sides, or drains. With regard to the city authorities, wastes are collected and transferred to ultimate disposal sites (UDSs). There is no engineering or sanitary landfill in Bangladesh. All the ultimate MSW disposal sites of Bangladesh are uncontrolled crude open dumping sites where even minimum environmental protections are not provided. Recycling, reduction, and reuse are not getting support from formal authority, even the composting, a great potential sector of waste treatment and minimization considering the nature of MSW in LDACs, fails to reach the desired target due to improper planning [79]. As a result, city authorities are facing very complicated situations for the management of the vast quantities of MSW. Due to financial constraints, lack of motivation, absence of effective legislation to protect the environment, and lack of commitment of authority, the MSW has been becoming a threat for city dwellers, planners, and other concerned stakeholders.

\section{Overview of Municipal Solid Wastes in Study Areas}

Bangladesh, the most densely populated LDAC, has nearly 150 million people living in a flat deltaic land of $147570 \mathrm{~km}^{2}$ area that lies between $20^{\circ} 34^{\prime}$ and $26^{\circ} 38^{\prime}$ north latitude

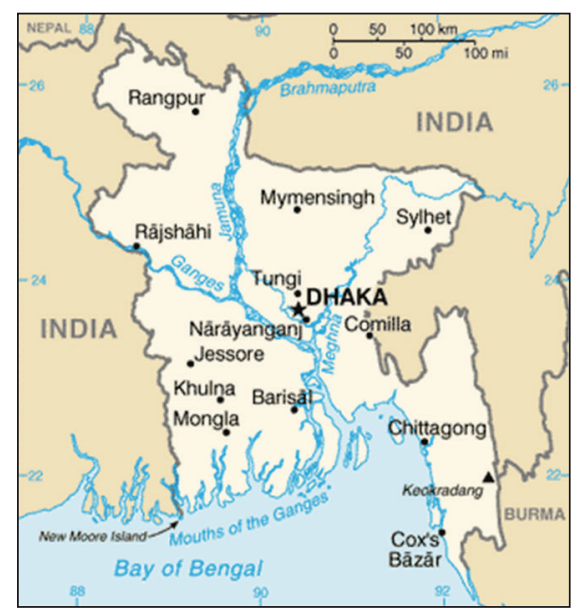

FIGURE 1: Location of study sites.

and $88^{\circ} 01^{\prime}$ and $92^{\circ} 41^{\prime}$ east longitude. The country is divided into six administrative divisions in the same names of the six major cities, namely, Dhaka, Chittagong, Khulna, Rajshahi, Barisal, and Sylhet. The six major cities are considered as the present study sites. There are approximately 17.50 million people living in these six city corporations [10], generating about 7500 tons of MSW daily. Table 1 provides the basic information of the six city corporations of Bangladesh. The detailed characteristics of the MSW and the scenario of UDS can be found in Alamgir et al. $[3,11,12]$ and Alamgir and Ahsan $[13,14]$.

\section{General Setup of MSW Management}

City authority is responsible for overall management of MSW in the city corporation areas. Generally, it consists of two functional departments-conservancy and engineering departments. Figure 2 shows the general setup of MSW management in the city corporation of Bangladesh. Conservancy department is responsible for solid waste management including other utility services. Furthermore the conservancy department supervises the wastes intensive workers for collection and transfer while the engineering department is responsible for operation and maintenance operations involved in the waste management cycle such as collection, on-site storage and transportation vehicles, and ultimate disposal sites. The salary of drivers and helpers of waste transfer vehicles is also maintained by the engineering section but salary and wages of wastes intensive workers are maintained by the conservancy department. Figure 3 shows the flow path of MSW from source to ultimate disposal, a typical way to handle it in Bangladesh. Wastes irrespective of types are generally deposited in the community bins and SDSs either by the dwellers themselves or by NGOs, CBOs, city authority, or private sectors. In general, city authority collects wastes from the secondary points and transfers to the designated UDSs. Major portions of inorganic nonhazards and slowly biodegradable organic wastes are recycled and reused in the generation points, in the secondary points, 
TABLE 1: Basic information of six city corporations of Bangladesh.

\begin{tabular}{lcccccc}
\hline City corporation & $\begin{array}{c}\text { City area } \\
(\text { sq. } \mathrm{km})\end{array}$ & $\begin{array}{c}\text { Population } \\
\text { (million) }\end{array}$ & $\begin{array}{c}\text { Number of } \\
\text { Wards }\end{array}$ & $\begin{array}{c}\text { Wastes generation rate } \\
\text { (kg/cap/day) }\end{array}$ & $\begin{array}{c}\text { Total generation } \\
\text { (tons/day) }\end{array}$ & $\begin{array}{c}\text { Ultimate disposal site } \\
\text { Dhaka }\end{array}$ \\
Chittagong & 150 & 11.00 & 90 & $0.40-0.55$ & $5000-5500$ & 2 \\
Khulna & 47 & 3.65 & 45 & $0.30-0.45$ & $1200-1400$ & 2 \\
Rajshahi & 48 & 1.50 & 31 & $0.30-0.40$ & $420-520$ & 1 \\
Barisal & 45 & 0.45 & 30 & $0.25-0.35$ & $160-210$ & 1 \\
Sylhet & 26.5 & 0.40 & 30 & $0.20-0.25$ & $100-140$ & 1 \\
\hline
\end{tabular}

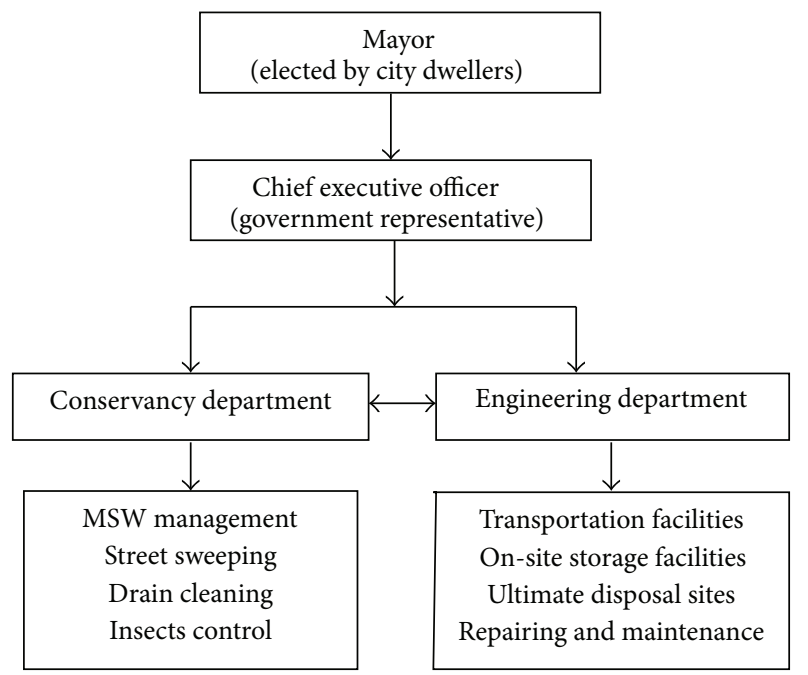

FIGURE 2: General setup of MSW management in the city corporation of Bangladesh.

and even in UDSs. Composting is one of the common options for treatment and reuse of organic portions of MSW is done in a very small scale by dwellers, NGOs, private sectors, and even city authority. However, major portions of wastes remain unmanaged-throwing them in the adjacent spaces, roadsides, and drains. A portion of clinical wastes is managed by NGOs [15] and the remaining follows in the same path of MSW.

\section{Source Storage and Collection of Wastes}

Residential wastes are the main sources of MSW in Bangladesh. The other important sources are commercial wastes including markets, hotels, and restaurants, hospital/clinical wastes, institutional wastes including schools, colleges, universities, and government offices, construction and demolition wastes, and municipal services wastes such as street sweeping, drain cleaning but excluding treatment facilities. In Bangladesh, a significant portion of population does not have access to waste collection services and only a fraction of the generated wastes are actually collected by door-to-door collection systems introduced by NGOs and CBOs in late 90s in Bangladesh for tiny payment. Moreover, due to a lack of motivation, awareness, and commitment, a considerable portion of wastes, $40-60 \%$, are not properly stored, collected, or disposed in the designated places for ultimate disposal. As a result, the unmanageable increasing quantity of MSW creates alarming environmental problems.

Residents participating in the existing solid waste management system store their solid wastes in plastic or metal containers of different sizes and shapes and keep them inside their house or premises, mostly in the kitchen and/or corridor. Waste collection workers collect the container, then dispose it into the collection van, and return the empty container. Study reveals that source storage and separation of organic, inorganic, and hazardous wastes are highly neglected by the city dwellers. Generally, commingled solid wastes are collected in single-compartment vehicles. Where door-todoor collection systems are not available, house dwellers or servants carry wastes to nearby community bins/secondary sites on their own. The waste collection trucks collect the wastes at regular intervals for ultimate disposal. Households store the wastes at their own responsibility; however, some NGOs and CBOs even supply the bins to motivate people to cooperate with waste management system. Experiences reveal that proper storage and disposal are first steps to achieve the desired goal of solid waste management. Motivation of house owners and the door-to-door collection are proven to be very useful. However, the city authority has the lack of resources (e.g., manpower and budget) to provide the door-to-door collection system for each house [16]. Chittagong and Rajshahi city authorities are involved in the door-to-door collection system [17]. In Khulna, total management in a ward (out of 31 wards) including door-todoor collections has been running by a private sector for the last 10 years. Figure 4 shows the wastes collection system from generation sources and disposal. The role of NGOs and CBOs in waste management is reported by Ahsan et al. [16].

\section{On-Site Storage}

On-site storage spaces are the SDSs, transfer stations, and handover points, which receive wastes from primary sources and then the wastes are transferred from this point to the designated location for processing/recycling/treatment and mostly for ultimate disposal. There is no transfer station or handover point in Bangladesh in a true sense. The SDSs are considered as the facilities where large amounts of wastes are accumulated and finally transferred to the desired sites by large vehicles such as open or closed trucks and demountable 


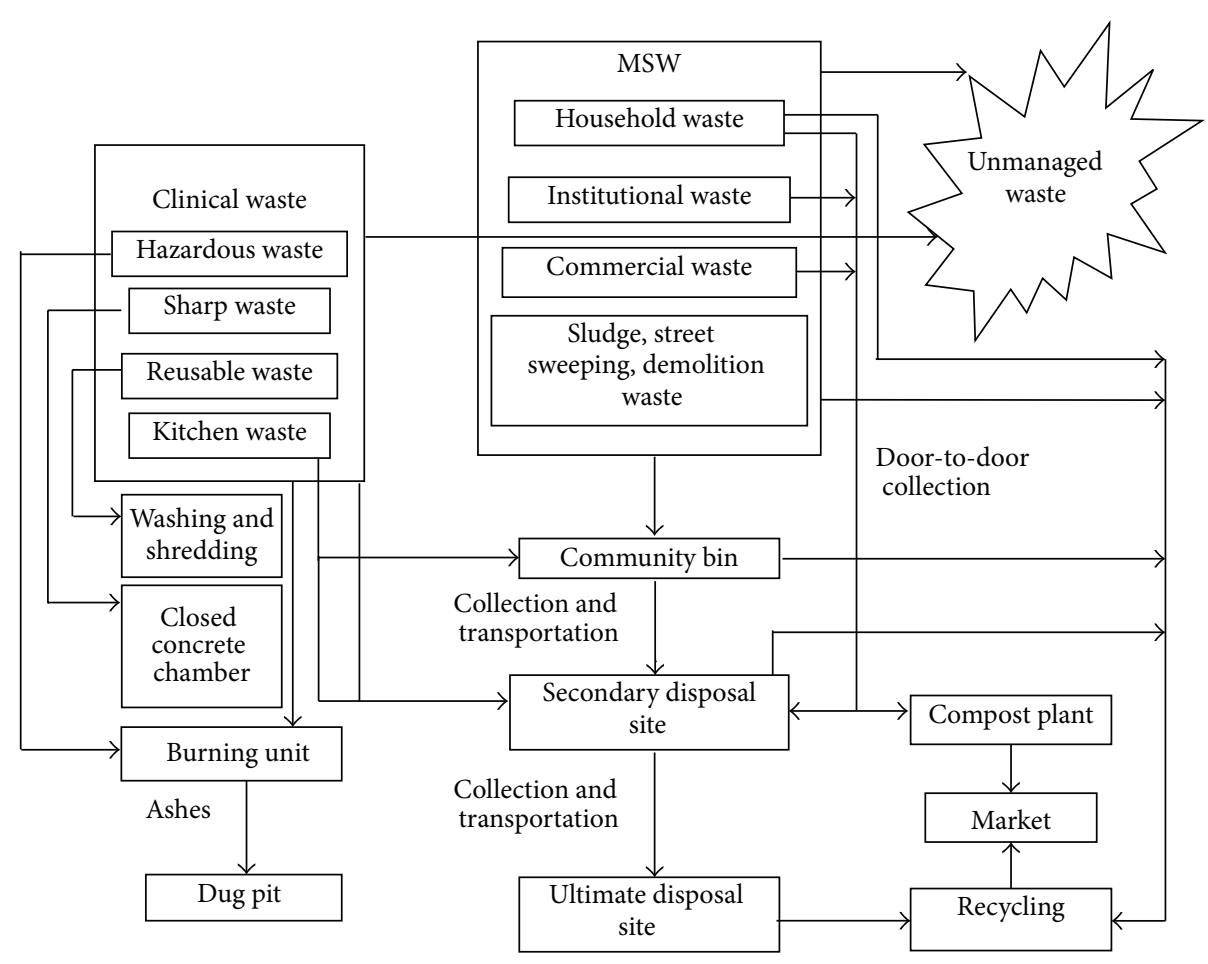

FIGURE 3: Flow diagram of MSW management in Bangladesh.

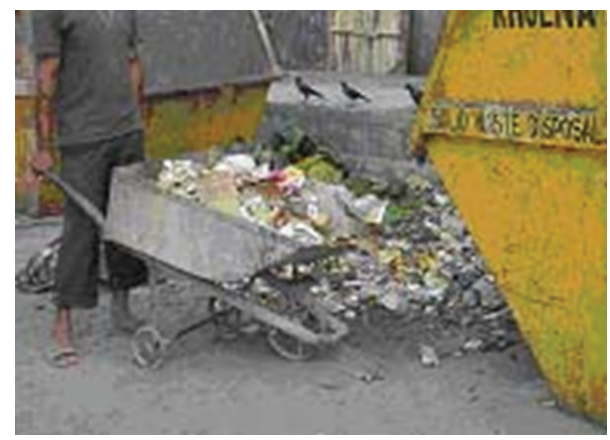

(a)

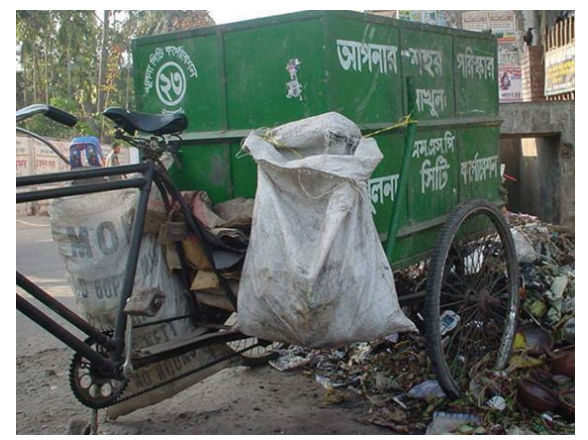

(b)

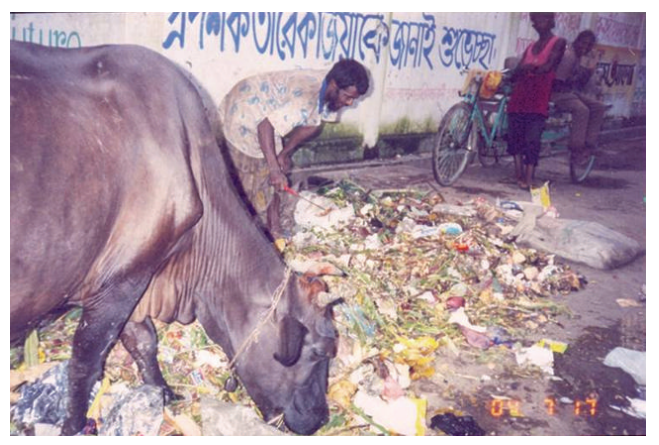

(c)

FIGURE 4: Wastes collection from generation sources and disposal in secondary points. 


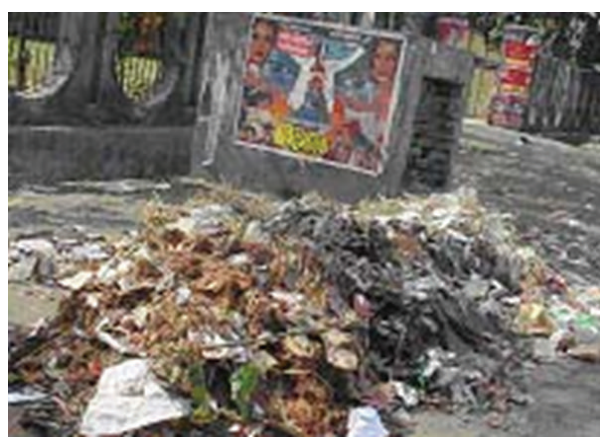

(a)

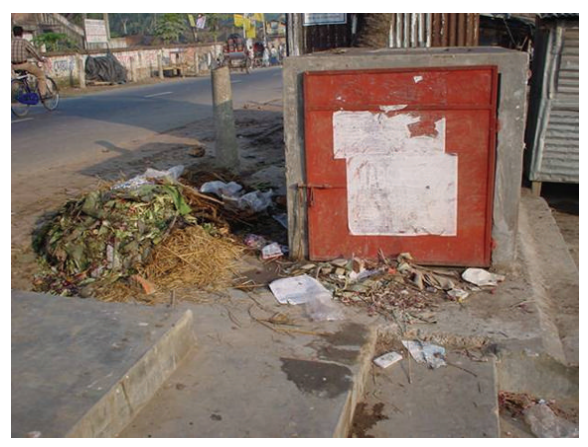

(b)

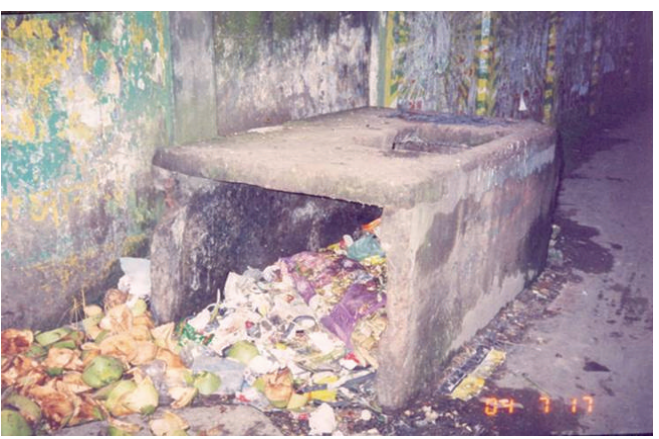

(c)

FIGURE 5: Secondary disposal sites of MSW.

haul container truck. A SDS may be an open space or roadside accumulation of solid wastes. They are large concrete bins, demountable large steel haul container, roadside spaces, and unused open low-lying areas. In Bangladesh, city authority is solely responsible for providing SDS, collecting wastes from SDS, and transferring for final disposal as per existing city corporation act. These sites are located in the selected places based on population, space availability, accessibility, and other unseen factors. Wastes are deposited in SDS (Figure 5) directly by the generators, NGOs, CBOs and city authorities. In some cases, especially for the residential areas along narrow streets where SDS is not suitable to provide, community bins are provided, from where wastes are transferred to SDS. A wide variety of types and shapes of community bins are built by the civic bodies and/or city authorities, which are located on the roadsides at frequent intervals. Community bins are mostly made of concrete but masonry and steel containers are also available. The concrete and masonry bins are in variable sizes but normally rectangular in shape which is one-meter wide, one-meter high, and one-/two-meter long. Generally, there is a door at one side and no cover on the top of the community bins. Wastes from community bins are transferred to SDS mostly by city authorities through nonmotorized rickshaw van and hand trolley.

In Dhaka City Corporation (DCC) areas, there are more than 846 SDS, 640 community bins, and 206 waste containers. For the last 2 years, two private organizations (in 6 wards) disposed the wastes from SDSs to UDSs. They built their own SDS (with a large area) and practiced better management. In Chittagong City Corporation (CCC) areas, the total number of SDS and community bins is 1506: 849 masonry bin, 66 concrete bins, 32 steel container, and 558 open spaces. Besides, there are huge numbers of unauthorized small dumping sites spreading throughout CCC. In Khulna City Corporation (KCC), there are more than 60 SDSs, around 1200 community bins, and 28 haul containers located on roadsides throughout the city. In Rajshahi City Corporation (RCC) areas, there are 44 open types SDSs and about 190 community bins spreading over the whole city. There are no dustbins in RCC areas; recently all the dustbins have been removed from SDS. Rickshaw van pullers collect wastes from different sources and dump them into the open spaces randomly at SDS. There are 150 SDSs in Barisal City Corporation (BCC) areas spearing unevenly over the whole city; as a result, some wards of BCC do not have SDS. In Sylhet City Corporation (SCC) areas, there are about 74 SDSs out of which only 30 to 35 sites are in use. In general, the SDSs have bin(s) made of concrete or masonry. Recently, three largesized SDSs with better facilities have been constructed with the assistance of an NGO.

In the MSW management tier, SDS plays a very pivotal role. However, the situations of SDSs in all city corporations are very much unpleasant and alarming. The SDSs are deteriorating the city environment at a large scale as shown in Figure 5. Since SDS, situated mostly at busy roadsides, receives and delivers wastes, proper management with very strict timing for collection and transfer is required which cannot be addressed by the city authority with existing management system, so alternative options of SDS should be considered. In the meantime, BCC already demolished all 


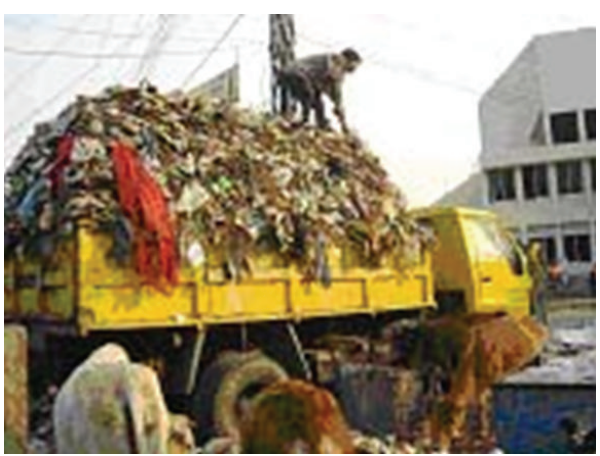

(a)

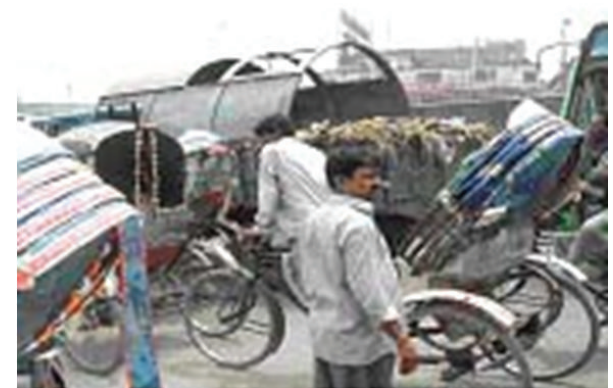

(b)

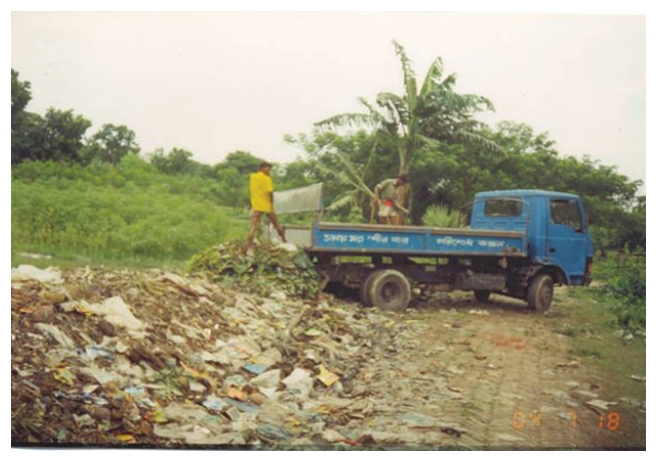

(c)

FIGURE 6: Wastes collection, transportation, and ultimate disposal.

the permanent structures in SDS, while SCC is not using some points of SDS and already removed roadsides littering boxes. DCC is preparing a master plan and KCC is considering building a transfer station as an experimental station. In such situation, options should be kept open to solve these problems either by transfer station or handover points.

\section{Transportation}

The functional element of collection includes not only the gathering of solid wastes and recyclable materials but also the transportation of these materials after collection, to the location where the collection vehicle is emptied. Only respective city authority is responsible for collecting wastes from secondary points and transporting them by motorized vehicles/trucks and finally disposing them in the designated UDS(s) of the city. Although NGOs and CBOs collect wastes from households/generation points and dump them in the SDSs, they do not take responsibility for the collection and transportation of wastes from SDSs. However, in DCC it is found that two private companies have been collecting and transferring wastes from SDS to the city authority's UDSs for the last 2 years. These two private companies served only 6 wards out of 90 wards on a contract basis. In KCC, a private company has been collecting and transporting wastes for dumping them in the UDS for the last 10 years only in one ward out of the existing 31 wards.

Conservancy department set up the time schedule and fix vehicles for collection and transportation. Generally, collection vehicles such as dump truck, normal truck, open truck, tractor with trolley, tipping truck (container carrier), desledging vacuum tanker with tractor, and power tiller with trolley stand on the road nearby the SDS for operation. Staff are assigned with each vehicle for collection and disposal. Demountable containers are only hauled by tipping truck and no workers are required for collection and disposal but its numbers are also limited. Wastes are mostly collected in daytime obstructing the movement of pedestrians and traffics and also transported through busy city areas creating nuisance and pollution due to being overheaped and uncovered and due to leakage of liquid from the wastes as shown in Figure 6. City authority does not have the required number of vehicles and staffs to perform the operation successfully. Besides, the present management system is not capable of utilizing the existing resources properly. As a result, the collection of wastes from SDSs is very disappointing and creating a lot of hazards as wastes remain there for longtime. Table 2 shows the total number of motorized vehicles and amount of wastes collected, transported, and dumped in the studied sites.

\section{Ultimate Disposal Sites}

The safe and reliable long-term disposal of solid wastes is an important component of integrated waste management. Although source reduction, reuse, recycling, and composting can divert significant portions of MSW, a large amount of wastes still needs to be placed in landfills. There is no 
TABLE 2: Number of motorized vehicles with transport capacity.

\begin{tabular}{lcc}
\hline City & $\begin{array}{c}\text { Number of } \\
\text { motorized vehicles }\end{array}$ & $\begin{array}{c}\text { Amount collected, } \\
\text { transported, and dumped } \\
\text { (tons/day) }\end{array}$ \\
\hline Dhaka & 373 & $2000-2400$ \\
Chittagong & 49 & $500-550$ \\
Khulna & 32 & $240-260$ \\
Rajshahi & 15 & $60-80$ \\
Barisal & 7 & $30-40$ \\
Sylhet & 17 & $60-80$ \\
\hline
\end{tabular}

controlled/engineered/sanitary landfill in Bangladesh. The sites are situated in and around the city areas of low-lying open spaces, unclaimed lands, riverbanks, and roadsides. DCC and CCC, each operates at two sites, namely, Matuail and Gabtali and Raufabad and Halishahar, respectively, while other city corporations operate at one site each, namely, Rajbandha, Shishu Park, North Kawnia, and Lalmati. All types of MSW are disposed including some portions of medical/hospital wastes. Crude open dumping sites are always incompatible with the surroundings. Wind blows wastes to the surroundings. No proper land filling system is followed. Wind blows litters and spreading wastes outside the site and on the surrounding pond and adjacent surface water.

Environmental pollution at open dumping site may include air pollution, water and soil contamination due to generation of leachate, gas, odor, dust, and potential fire hazard. The uncontrolled burning of solid waste creates smoke and other types of air pollution. Garbage nuisance conditions also pose higher risks for human beings. As major parts of disposed wastes are biodegradable organic wastes, anaerobic decomposition gases are generated continuously. However, there is no provision for the management of these gases in existing sites, causing risk of explosions and fire hazard. In UDS, leachate may percolate and contaminate surface and ground water because these sites are not designed for leachate containment. The sources (tube-well) of groundwater are very close to the UDS. People use this water for different purposes like bathing, washing, drinking, and farming. Surface water is also contaminated because solid wastes are dumped near/at the marshy land, ponds, rivers, and canals. Contaminated water is harmful for fish and aquatic lives by reducing the amount of dissolved oxygen in the water. Chemical and oil constituents, which are usually mixed with MSW, can also cause severe water contamination that may kill water birds, shellfish, and other wildlife. Figure 7 shows the current scenario of UDSs. Details can be found in Alamgir et al. [3, 12] and Mohiuddin et al. [18].

The possible ways to reduce/remove the environmental pollution at the UDS are as follows: (i) a few gas flaring units can be installed in different locations to burn the small amount of gas and (ii) a thick clay liner using local soil can be installed before dumping the waste in any new locations to protect the leachate percolation/contamination.

City authorities are facing problems to get new sites for ultimate disposal. Due to nonengineered situation, the existing sites are also going for early closure. People also protested to close the existing sites because of nuisance. The existing method, that is, crude open dumping for ultimate disposal, is not supported by concerned environmental experts/stakeholders. Therefore, the city authority is thinking of upgrading the existing sites to control the negative impacts of the existing situation and may propose an environmentally safe sanitary landfill in accordance with local conditions and technological and financial capabilities.

\section{Waste Minimization and Treatment}

The MSW management includes and is not limited to the following components: source control, reuse, recycling, composting, land filling, and energy recovery. In the studied cities, there is no controlled or planned waste minimization program. Most of the recycling activities are conducted by self-employed workers or scavengers as shown in Figure 8.

8.1. Recycling. Recycling is the reprocessing of wastes, into either the same product (closed loop recycling) or a different product (open loop recycling). It is the key mechanism to recover useful products and reduction in waste quantity. Source separation is the best process where different categories of recyclables and organics are separated at source, that is, at the point of generation, to facilitate reuse, recycling, and composting. Informal sectors by various groups of community are playing an important role in recycling of solid waste in Bangladesh. All the buyers of the recyclable items belong to the informal sector and only a few formal manufacturers are involved in using recyclable substance as raw material. However, in the studied areas, recycling is not practiced widely and effectively except for certain urban areas.

In Bangladesh, generally recycling is carried out in three phases. Phase one is the source separation, where the generators separate refuse of higher market value such as papers and paper products, bottles, fresh containers, plastic materials, tin, glass, metal, old clothes, and shoes and sell these things to street hawkers. Hawkers collect reusable and recyclable materials from house to house and sell them to nearer "Vangari Dokans" (recycling shops). In the second phase, the poor children of slum dwellers known as "Tokai" are collecting different items of low market value from onsite storage bins/containers and open storage spaces. The items include broken glass, cans, cardboard, waste papers, rags, pet bottles, coconut shells, metals, and miscellaneous commercial waste discarded by householders. The final phase is the recovering of reusable and recyclable materials from UDSs. Scavengers (Tokai) collect recyclable items mainly when collection vehicles are being unloaded at dumping site. The reclaimed materials are sold to Vangari Dokans by scavengers where intermediate processing like washing, drying, and sorting is carried out in proper form and sell these things to whole sellers. Ultimately, all reclaimed materials are supplied to the appropriate processing factories for reuse as raw materials. Plastic materials, in small scale, are also exported to the capital city after shredding and cleaning. 


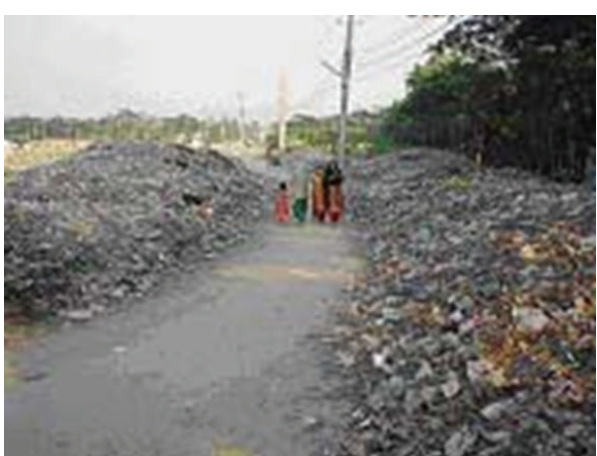

(a)

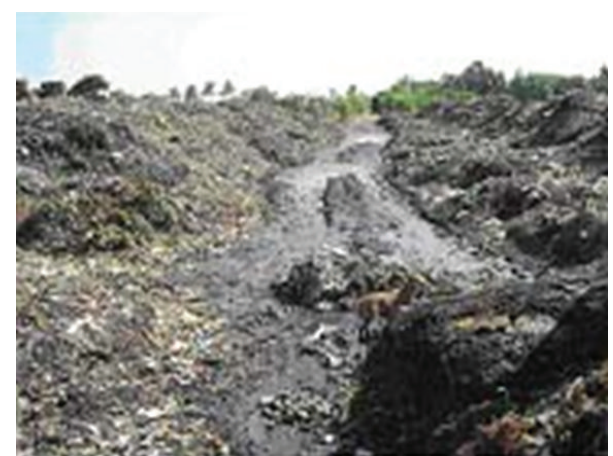

(b)

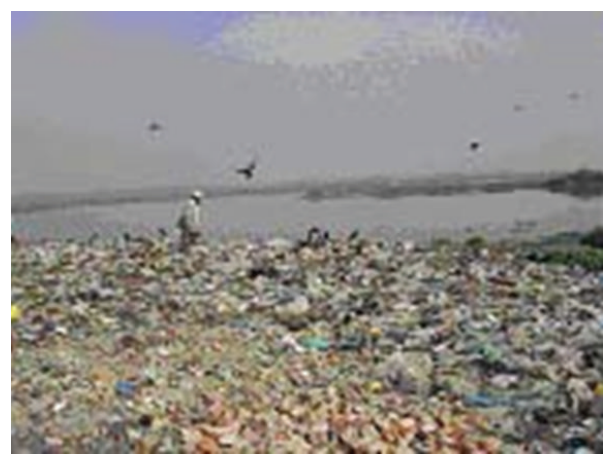

(c)

Figure 7: Typical ultimate disposal sites of MSW in Bangladesh.

Figure 8 shows the scenario of scavenging of recyclable materials in a SDS and UDS. However, the ultimate success of waste minimization might depend on the establishment of a good market price of these recovered materials. A few local small industries fully depend on the availability of reclaimed material for reprocessing. Commonly nonhazardous wastes are recycled in Bangladesh; however there is a strong need for recycling of hazardous or special wastes (e.g., solvents).

8.2. Composting. Another form of recycling is composting. Controlled biological decomposition of organic wastes produces a soil-like material known as compost. Composting is nature's way of recycling organic wastes into new soil used in vegetable and flower gardens, landscaping, and many other applications. The MSW of Bangladesh is suitable for composting due to its high moisture and organic contents. In Bangladesh, mainly NGOs are involved in composting. They are involved in composting of organic wastes in 4 city corporations, namely, Dhaka, Chittagong, Khulna, and Sylhet. There is no compost plant in Barisal and Rajshahi city. Besides the city corporation areas, compost plants are also set up in some municipalities with technical supports from experienced NGOs, financial support from donor agencies with the collaboration of local city authorities. Recently, private companies have also come forward to invest in this sector. However, this sector is also facing several problems such as finance, appropriate technology, land, proper location, supply of wastes, quality of wastes, quality of compost, and marketing facilities. Recently, a compost plant in Sylhet was forced to stop its operation due to the objection from adjacent inhabitants. The situation of the surveyed compost plants is also not encouraging [3]; some of them are in a stage of closing the operation for the inherent reasons. In general, health and hygienic aspects are absent in all the compost plants. The staff are not properly trained and even do not care of using personal protective equipments. Most of them have been suffering from persistent diseases such as cough, allergy, and skin problem $[19,20]$.

\section{Integrated MSW Management Approach}

As there is no "solution" for MSW problems; an approach is required for evaluation, analysis, and synthesis of all aspects necessary for the selection of an ISWM suitable for Bangladesh. The approach is to seek the improvement of waste management through (i) a structural dialogue between stakeholders and (ii) the planning and implementation of change. The dialogue aims to promote desirable checks and balances between the focus and motivation of specific interests through a modern spreadsheet: (i) to promote a device to think the problems systematically and holistically, and (ii) to help for setout more selectively a balanced "business and sustainability" for some proposed intervention action. The common spreadsheet format consists of (i) waste system components forming the row headings of the spreadsheet, that is, contain and collect; sort and recover; transfer and treat; and dispose and make safe, and (ii) aspects of evaluating components forming the column headings of 


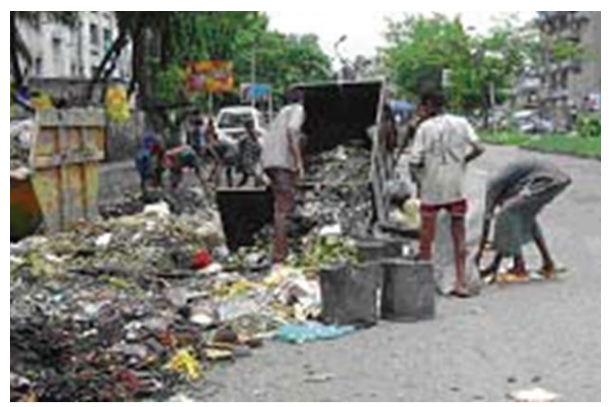

(a)

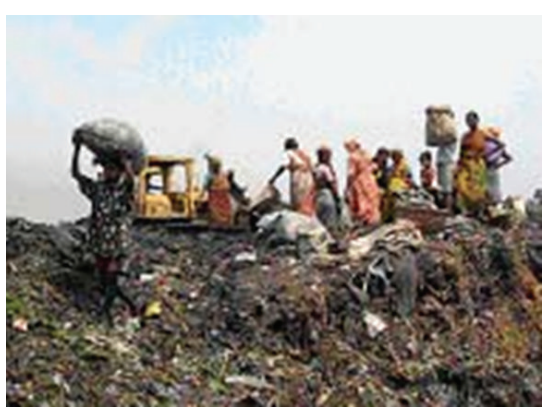

(b)

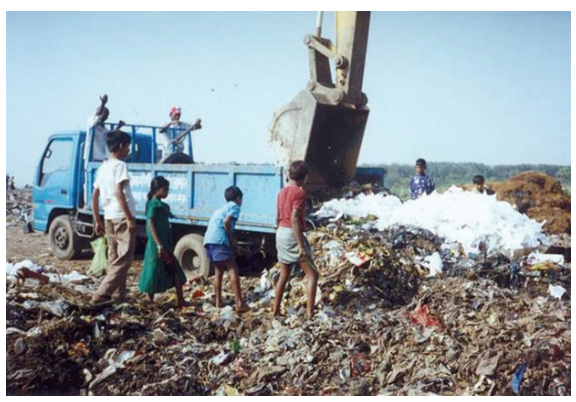

(c)

FIGURE 8: Scavengers collect recyclable materials in SDS and UDS.

the spreadsheet, that is, sources and streams; costs and returns; health and environment; and community and structure. The municipal authority may decide to set up four working groups, corresponding to the four elements: contain and collect, sort and recover, transfer and treat, and dispose and make safe (after [21]).

The municipal authority may appoint independent chairpersons, involved representatives from key stakeholders, and organized technical support and wider consultative processes for each group. Overall programming and coordination are provided by the municipality itself. When the functional elements of the waste management services have been evaluated and selected and all the interfaces and connections between elements have been matched for effectiveness and economy, the concerned stakeholders/authorities/communities are said to have developed an integrated waste management system. The IMSW management is defined by researchers and academics as the selection and application of appropriate techniques, technologies, and management programs to achieve specific waste management objectives and goals. Understanding the interrelationships among various waste activities makes it possible to create a plan in which individual components complement one another. Figure 9 shows a model for the major elements of ISWM, which is modified of proposed one by Visvanathan et al. [21].

In general, the situation of MSW management in Bangladesh is very alarming, poses serious health threats to humans and nature, and demands immediate and sustainable solutions. The study concludes that the problems will only be solved by introducing IMSW management systems, based on local needs and socioeconomic conditions to ensure environmental sustainability.

\section{Conclusions}

Rapid urbanization and population growth in the major cities of Bangladesh creates a huge generation of MSW and the authority is unable to manage properly with the present management system, economic support, human resources, infrastructures, and technological capabilities. Door-to-door collection system needs to get support from all stakeholders with proper awareness, motivation, and commitment campaign. Existing on-site storage practices should be changed immediately by adopting properly designed and maintained secondary disposal sites or transfer stations or handover points, where it is applicable based on the prevailing socioeconomic aspects. Efficiency of wastes transportation to the ultimate disposal sites (UDSs) must be improved with the participation of private sector with strict terms and conditions. Present situation of UDSs requires improvement by providing a sanitary landfill mechanism in the existing sites. Recycling can be extended with wide varieties of articles both in the formal and informal sectors. Government support should be provided in composting, a prosperous sector for managing a huge amount of organic wastes in Bangladesh. Since there is no single solution, the proposed techniques can be used to select an integrated solid waste management 


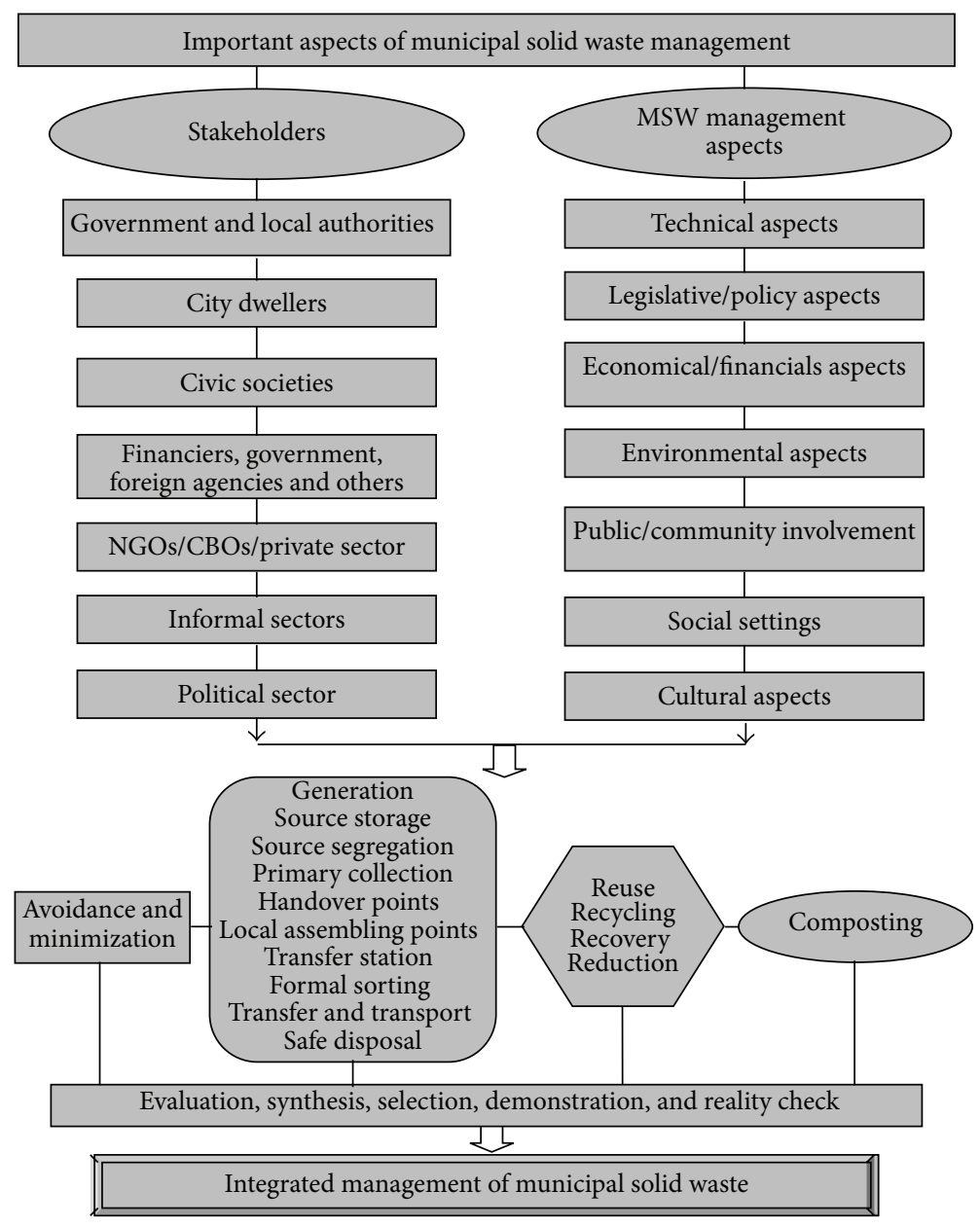

Figure 9: Major elements of integrated MSW management.

system based on the local needs, socioeconomic settings, and technological capabilities to ensure the acceptability of the adopted system and the environmental sustainability.

\section{Conflict of Interests}

The authors declare that there is no conflict of interests regarding the publication of this paper.

\section{Acknowledgment}

The partial financial support of the European Union's Asia Pro Eco Programme of Contract no. ASIA PRO ECOASI/B7-301/2598/16-2004/79010 for this study is gratefully acknowledged.

\section{References}

[1] G. Tchobanoglous, T. Hilary, and V. Samuel, Integrated Solid Waste Management: Engineering Principles and Management Issues, McGraw-Hill, New York, NY, USA, 1993.

[2] G. Tchobanoglous and F. Kreith, Handbook of Solid Waste Management, McGraw-Hill, New York, NY, USA, 2002.
[3] M. Alamgir, C. McDonald, K. E. Roehl, and A. Ahsan, Eds., Integrated Management and Safe Disposal of Municipal Solid Waste in Least Developed Asian Countries: A Feasibility Study, WasteSafe Publication, Khulna, Bangladesh, 2005.

[4] A. Ahsan, N. Ismail, M. M. Rahman et al., "Municipal solid waste recycling in Malaysia: present scenario and future prospects," Fresenius Environmental Bulletin, vol. 22, no. 12a, pp. 3654-3664, 2013.

[5] M. A. A. Samah, L. A. Manaf, A. Ahsan, W. N. A. Sulaiman, P. Agamuthu, and J. L. D'Silva, "Household solid waste composition in Balakong City, Malaysia: trend and management," Polish Journal of Environmental Studies, vol. 22, no. 6, pp. 1807-1816, 2013.

[6] M. A. A. Samah, L. A. Manaf, P. Agamuthu, W. N. A. Sulaiman, and A. Ahsan, "Real data composition of municipal solid waste (MSW) generated in Balakong, Selangor, Malaysia," Life Science Journal, vol. 10, no. 4, pp. 1687-1694, 2013.

[7] M. Ali, Sustainable Composting: Case Studies and Guidelines for Developing Countries, WEDC, Loughborough University, Leicestershire, UK, 1st edition, 2004.

[8] A. M. Sinha and I. Enayetullah, Community Based Solid Waste Management: The Asian Experience, Waste Concern, Dhaka, Bangladesh, 1st edition, 2000.

[9] I. Enayetullah and A. M. Sinha, Decentralized CompostingThrough Public-Private-Community Partnership: Experience of 
Waste Concern, Waste Concern, Dhaka, Bangladesh, 1st edition, 2003.

[10] BBS, Bureu of Statistics, Bangladesh Bureau of Statistics, Dhaka, Bangladesh, 2001.

[11] M. Alamgir, K. H. Chowdhury, K. E. Roehl, E. I. Stentiford, and Q. H. Bari, "Basic characteristics of municipal solid wastes of Bangladesh," in Proceedings of the Conference on Waste-The Social Context, vol. 17, pp. 1-6, Edmonton, Canada, 2005.

[12] M. Alamgir, K. M. Mohiuddin, K. A. Czurda, U. Glawe, and M. R. Karim, "Situation of ultimate disposal sites of municipal solid wastes in Bangladesh," in Proceedings of the Conference on Waste-The Social Context, vol. 18, pp. 1-9, Edmonton, Canada, 2005.

[13] M. Alamgir and A. Ahsan, "Municipal solid waste and recovery potential: Bangladesh perspective," Iranian Journal of Environmental Health Science and Engineering, vol. 4, no. 2, pp. 67-76, 2007.

[14] M. Alamgir and A. Ahsan, "Characterization of MSW and nutrient contents of organic component in Bangladesh," Electronic Journal of Environmental, Agricultural and Food Chemistry, vol. 6, no. 4, pp. 1945-1956, 2007.

[15] M. Alamgir, K. H. Chowdhury, and Q. S. Hossain, "Management of clinical wastes in Khulna city," in Proceedings of the Conference on the Role of Renewable and Alternative Energy Sources for National Development, pp. 146-155, Khulna University of Engineering and Technology, Khulna, Bangladesh, 2003.

[16] A. Ahsan, M. Alamgir, M. Imteaz, N. N. N. Daud, and R. Islam, "Role of NGOs and CBOs in waste management," Iranian Journal of Public Health, vol. 41, no. 6, pp. 27-38, 2012.

[17] K. H. Chowdhury, M. Alamgir, Q. H. Bari, and M. K. Chowdhury, "Collection system of solid waste from source in Rajshahi city, Bangladesh," in Proceedings of the 3rd Annual Paper Meet and International Conference on Civil Engineering, pp. 25-33, IEB, Dhaka, Bangladesh, 2005.

[18] K. M. Mohiuddin, M. Alamgir, and K. E. Roehl, "Present scenario of solid wastes disposal sites in Khulna city of Bangladesh," in Proceedings of the 3rd Annual Paper Meet and International Conference on Civil Engineering, pp. 429-438, IEB, Dhaka, Bangladesh, 2005.

[19] H. An, J. Englehardt, L. Fleming, and J. Bean, "Occupational health and safety amongst municipal solid waste workers in Florida," Waste Management and Research, vol. 17, no. 5, pp. 369-377, 1999.

[20] M. R. Ray, S. Roychoudhury, G. Mukherjee, S. Roy, and T. Lahiri, "Respiratory and general health impairments of workers employed in a municipal solid waste disposal at an open landfill site in Delhi," International Journal of Hygiene and Environmental Health, vol. 208, no. 4, pp. 255-262, 2005.

[21] C. Visvanathan, J. Trankler, Z. Gongming et al., Municipal Solid Waste Management in Asia: Asian Regional Research Program on Environmental Technology (ARRPET), AIT, Pathumthani, Thailand, 2004. 

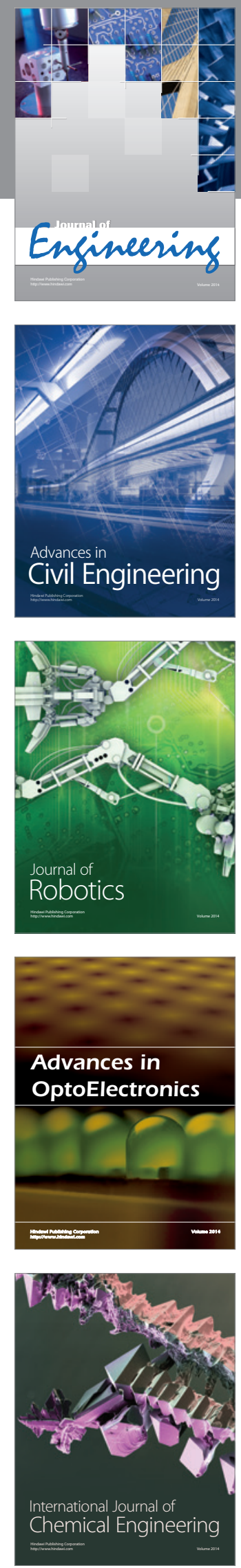

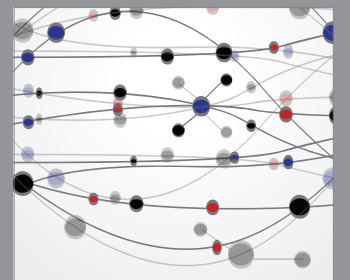

The Scientific World Journal
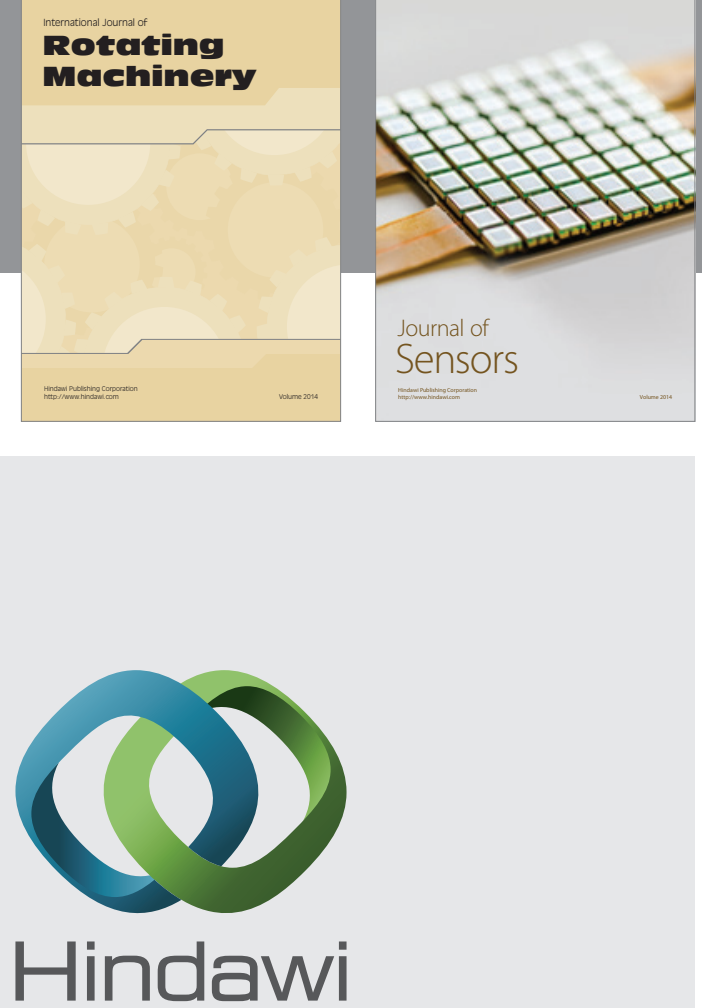

Submit your manuscripts at http://www.hindawi.com
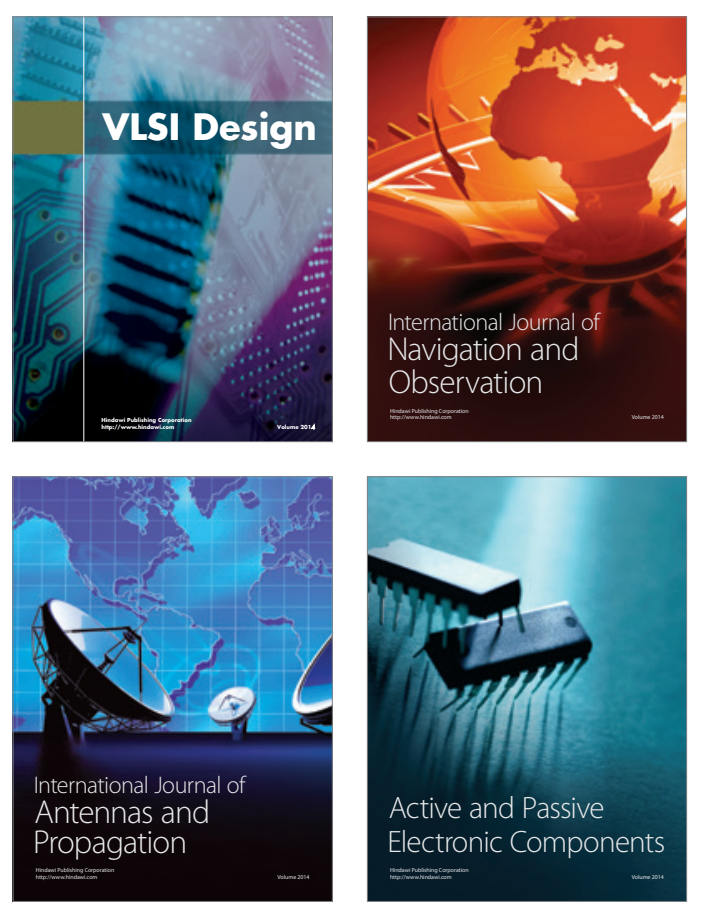
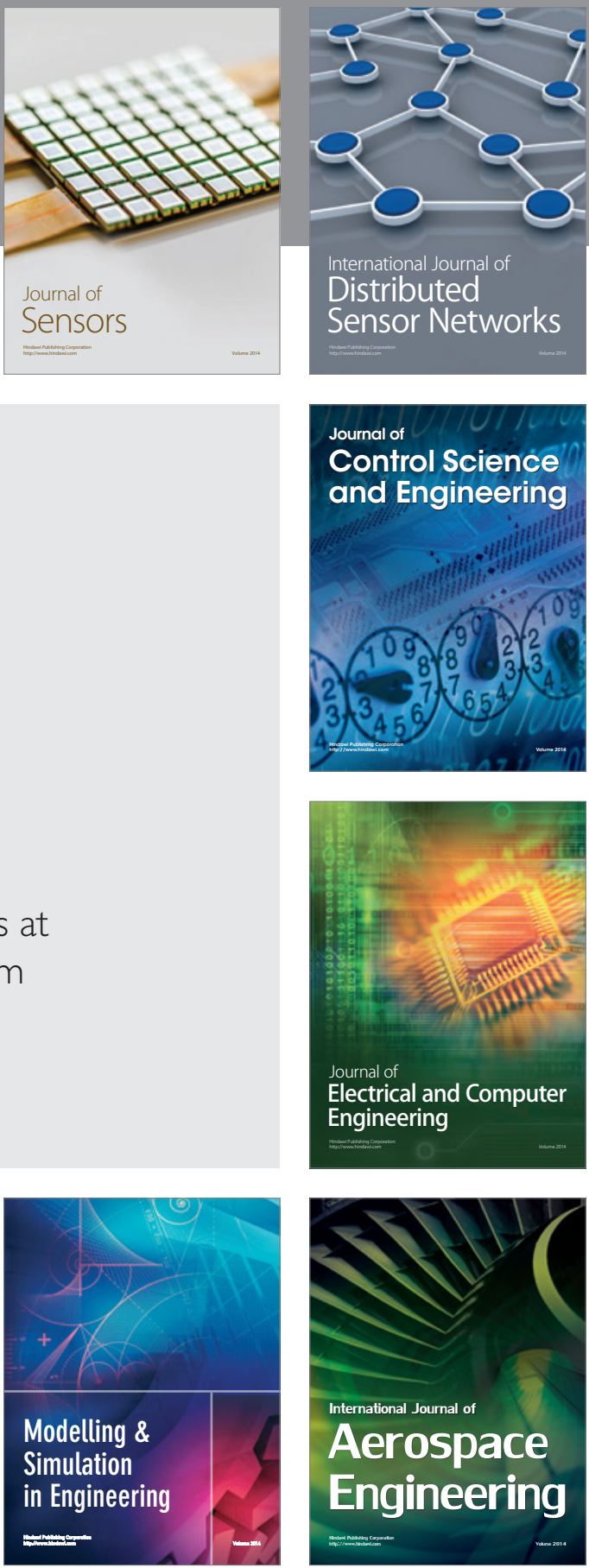

Journal of

Control Science

and Engineering
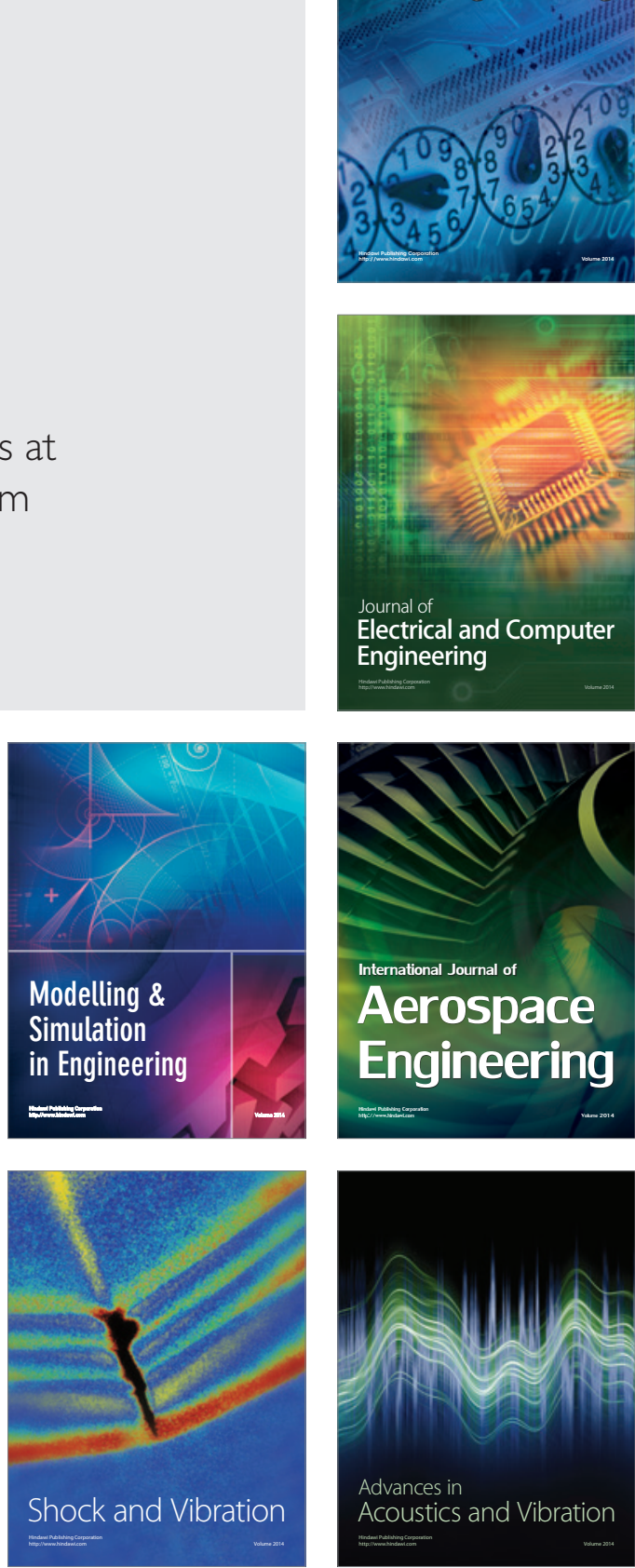